\title{
Benzhu Worship Analysis of the Bai Residential Gatehouse in Dali Xizhou
}

\author{
Long Jiang \\ Panzhihua University \\ Panzhihua, Sichuan, China 617000
}

\author{
Liu Yang \\ Panzhihua University \\ Panzhihua, Sichuan, China 617000
}

\begin{abstract}
This article based on field research of 115 Xizhou Bai residential gatehouses,take Youxia gatehouse (hereinafter abbreviated gatehouse) as the study object, analyze Benzhu worship expression through its architectural form, creation process and ritual, so to study the unique humanistic care of the Bai people.
\end{abstract}

Keywords—Bai nationality; gatehouse; Benzhu worship

\section{INTRODUCTION}

The Bai language for Benzhu is "Wu Zeng", "Zeng Ni", etc., which means "our master", in early Chinese described as "master of the land", "Benefactor of the land", "Blessed master of the land" and so on. Benzhu is Bai's "Patron God", almost every village has its own Benzhu and the Benzhu temple, Bai people who did not have their Benzhu called "Mu Zeng", they are the people with no master and they are despised.In Bai people's mind, Benzhu can bless villagers reach "Officers will have very successful career; Farmers will accumulate countless grains; Workers will have the skill to make all the things; Businessman will extend his business all over the world " [1]. Therefore, for individuals whenever weddings and funerals, building houses, pray for children or go out...all producing and living things; for group, it coordinate ethnic relations, sacrifice and all the holidays must go to Benzhu temple to worship.

The development of the Benzhu worship extensively absorb foreign cultures such as Confucianism, Taoism, Buddhism and other cultural ingredients, but after a lengthy localization, it emphasizes the "mundane" spirit, not for the afterlife, only pursuit earthly happiness. Bai is based on the idea of"sacrifice those who dead for serve the king, sacrifice those who make achievements to bring peace and stability to the country, sacrifice those who defend the huge disasters, sacrifice those who resist strong enemies" [2] to arrange the sacrifice activities, so Benzhu God has both secular emotions like joy, anger, sorrow, happy human natures but also has patron god's heroism, idealism characters, it is a God with human nature and a person with god nature. This is the uniqueness where Bai people's Benzhu worship is different from other faiths; it contains vivid and fresh humanity and also the carrier of people's good moral qualities and Bai people's good traditions.

Benzhu Culture Architecture is an important component and embodiment of Benzhu worship, this article will take the creation of Bai's traditional residential gatehouse as an example, to explore its unique humanistic care.

\section{OVERVIEW OF BAI'S GATEHOUSE}

The existing traditional Bai's folk residences in Xizhou mainly include Han-style Bai house and Tuku house two kinds. From the 123 residences I researched in Xizhou, Hanstyle houses are 118 , only 5 Tuku houses, from which we can see the entire view of Xizhou is formed by this mixed Han-style Bai residences. During this 118 Han-style Bai residences, 115 of them have obvious gate, which indicates the universality and importance of gate design in Bai's traditional residences. These 115 gatehouses can be divided into"Youxia gatehouse" and "Wuxia gate" two categories, 64 and 51 respectively. Due to record hundreds of years of vicissitudes, these traditional residences also become more unique, full-bodied and full of sentiment, especially reflected in the architectural style and features of gatehouse. This article will take Youxia gatehouse (hereinafter abbreviated gatehouse) as the study object.

Gatehouse, "Ying Zao Fa Yuan" explained as "Those who apply multiplicity of bricks over the door or add bracket and other decorations, above the room and its height exceed the walls on both sides." It is a gate with complex decorations which mainly use brick-wood structure, extension of bracket at top, door frame and door leaf installed in the middle. It is the entrance and appearance of a building, it has the function to divide and connect the space. "It not only represents the beginning of a building complex which takes the courtyard as the center, but also represents the end of the previous building. Door is media for the conversion from space to psychology, and also it is the connection point of all level space between the building complexes, it expands the depth of building complex and it has the function of opening, changing, developing and concluding in the overall space sequence."[3] Xizhou gatehouse has been standardized and modelized early in the Ming and Qing dynasties, construction was quite mature, and forms are also very fixed, usually to build one big and two small roofs above the door and the brick columns. These three arches,middle high and both sides low,wall do not need to load-bearing, door design and install are flexible and free, which has the function of external prevention, and also it is a symbol of the owner's wealth, status, taste and preference. It mostly use stone carving, wood carving, brick carving and 
other carving skills and painting decorations which are extremely fine and complex "Fig. 1".

According to the characteristics of architectural forms of the gatehouse it can be divided into angle type and flat type, the biggest difference is the overdoor. Angle type overdoor has wooden structure with ingenious components, below the eaves set a girder, above the girder set up a multi-layer extension of bracket in order to form the curved roof , the tow ends of the roof are highly tilted. Delicate wooden carvings on the brackets, and applied color painting, this roof of the overdoor has gable and hip roof , and hip roof tow kinds, the overall shape of the gatehouse is gorgeous and beautiful "Fig. 1". Flat type overdoor use masonry as its components, supported by the inverted arch, bricks build overlapped to extension the eaves, use brick carving or limestone to shape and decorate the beam under the eaves,there is painting on them too,the overall shape of the gatehouse is simple,dignified and generous "Fig. 2". Angle type and flat type gatehouse sometimes combined together, which means the middle roof use wooden structure angle type, and the two end use brick flat type "Fig. 3". The angle type gatehouse is very high-cost,almost equalled the cost for two floor three rooms, so mostly used by officers and businessmen; ordinary people use the flat type.

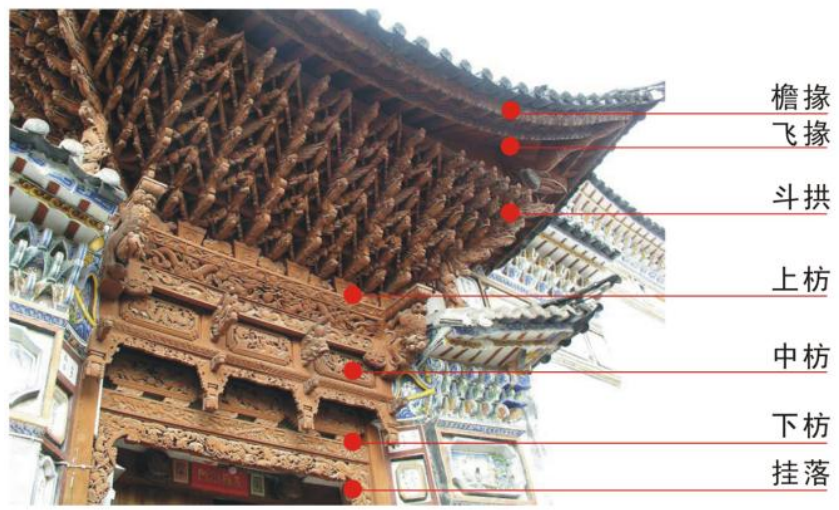

Fig. 1. Angle type Youxia gatehouse

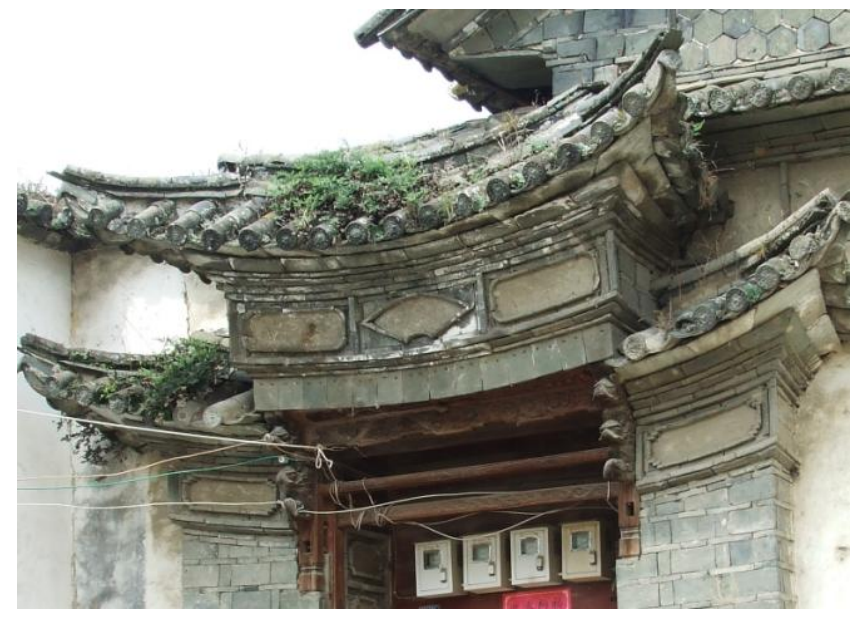

Fig. 2. Flat type Youxia gatehouse

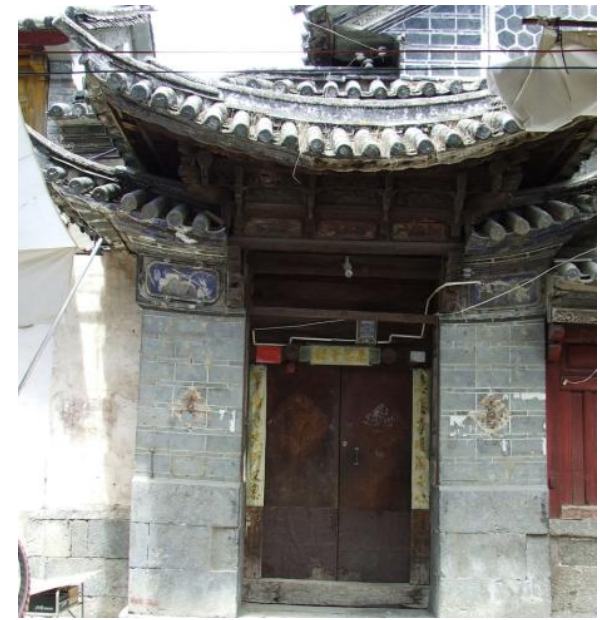

Fig. 3. Mix type Youxia gatehouse

\section{The Creation Process And Ritual of Gatehouse}

After the feng shui master determined the position and orientation of the central axis in outer room, according to the wind direction, environment, respect the left to determine the position and orientation of the gatehouse. Start building according to the auspicious date selected by feng shui master. Dong $\mathrm{mu}$ is the ritual to start carpentry. It also called Kaigong Jiama, a carpenter saw off a $5 \mathrm{~mm}$ thickness $\log$ sheet from central beam head which set up by wooden horses by the depth direction, and write "Yuan Mu Da Ji" on it vertically, which is $\mathrm{Mu}$ God. $\mathrm{Mu}$ God and $\mathrm{Tu}$ God put together and sacrifice every morning and night by burning incense. Mu God will be worshiped until set up the beam, then send it out. Dong tu is when the venerable elderly read the auspicious words, his left hand holding a hoe and hoe three times on the ground, then gather the soil to the auspicious position. Later set off firecrackers to celebrate the ritual has been finished, then you can lay the foundation at any time.

Laying foundation is generally carried out in the summer July and August, depth and width of the foundation ditch is based on the geology, generally $500 \mathrm{~mm}$ depth and $800 \mathrm{~mm}$ width are fine, it shows a trapezoid with big bottom and small top.There is often a symbolic "Xia Shi Jiao" ceremony, choose any corner of the foundation ditch to apply the stone material, sprinkle the "perfume" which made with cypress leaves powder and water at the selected footstone, meaning the house has a soundly foundation. When build up the footstone, they will put some Golden and silver jade at the four corners of the foundation ditch, which means "Zhen Bao"(treasures keep the house safety). The foot stones should be built overlapped, use mortar cement to caulking, grout, and fill in the gaps in each layer, strong and solid. After leveling the column footstone, they begin to ram earth wall. The specific method is sandwiched the wall by two large wooden boards, fill in the clay mixed by mortar, straw and water. Continually beat it with a fine-coarse wooden stick, while repeatedly stampede it at the same time. In this way the rammed earth wall will be strong and anti-seismic, have a long lifetime. 
Wait to the winter when the ground completely dried, after make tenons in the beams, place the beams on the ground according to the position and get ready to pull up the beams. Before pull up the beams, there is a "Send away $\mathrm{Mu}$ God" ceremony. In the evening, the chef carpenter sacrifice the beam which resting on two small wooden horses to the $\mathrm{Mu}$ and Tu two Gods; when to right time comes, put them in a bamboo basket. Then the second master carpenter use a hammer, knock from the middle beam sequentially in the order while shouting "Mu God please go out!" After know all the beams, set off firecrackers, the chef carry the bamboo basket outside the village where has water during the pound on drums and gongs, and burned the basket. The sacrificed log sheet was eventually sent to the water, there is meaning to avoid fire.

After send away the Mu God and set up the beam framework, then start to set red beam. After worship the founder (Lu Ban), worship the beam and been blessed by the monk, then life the beam up to the roof, tied red string on the beam. When you install first knock tight the tenon on the left end of the beam, then knock the right end and the middle, red beam installation is finish. Next install purlin, tiebeam and other components, and then the gate structure is stable.

\section{The Cultural Connotation of Gatehouse CREATING CEREMONY}

Start building, make the base and place the beam, these master and craftsman's acts and ceremonies still retain some Bai's traditional practices, it is a highly collaborative process, it is a result of the whole family members and craftsmen work together, it reflects the original mutual aid and friendly, which makes the site selection, material preparation, construction and completion are shrouded in mystery, contains a very strong religious content. As the "religion always externalized into various manifestations, in order to make these external manifestations become serious, solemn, mysterious, touching, showing devout religious feelings, it often by means of a variety of art forms." [4] Bai's gatehouse is the best art form to carry and express the Benzhu worship emotion; it passed in a vivid way from generation to generation. Because it is a cultural practices which approved both by villagers and craftsmen and it has a broad mass base, so it still exist as a vivid folk tradition. This Bai's unique cultural practices is the initiative spirit when they face the nature, it is a reasonable and positive life attitude. Through the prayer and worship of Benzhu, to reach "Officers will have very successful career; Farmers will accumulate countless grains; Workers will have the skill to make all the things; Businessman will extend his business all over the world." Its essence is to worship their strength, Benzhu is its manifestation. "Yi Gong Feng Shen", prominent secularity and participation, the Benzhu worship is merely dependent on the self-worship, is a representation of self-worship.And also is Bai people's good wishes and self-psychological suggestion to their life, themself, society and nature, is a concentrated expression of the Bai culture.

\section{CONCLUSION}

Bai's gatehouse uses its materialized language authentically record and reflect current living situation and pursue trend of Bai people. Although some of them are old etiquette thought, but after remove the unnecessary and overelaborate formalities and its pretensions ingredients, we can see more personality equality, friendship, mutual assistance and respect between people, as well as strong tolerance from them. Perhaps this is the basic reason why Bai's Benzhu worship continued until now, it emphasis to focus on human emotional experience and spiritual needs, and inject more emotions to the buildings so that the buildings carried more humanistic color, thus change the physical space into emotional space.

\section{REFERENCES}

[1] Yang Zhengye. Social and History Survey of Bai nationality (4) [M] Kunming: Yunnan People's Publishing Company. 1991.P67.

[2] The first volume of "Si Shu Wu Jing" "Li Ji", Yuelu Publishing Company, edition July 1990.

[3] Qin Li, "About the door" [M] Shandong: Shandong Pictorial Publishing Company. 2004,6.P9.

[4] Chinese culture annals editorial board. Chinese culture annals.Folk religion annals $[\mathrm{M}]$ Shanghai: Shanghai People's Publishing Company 2010.11.

[5] Wang Lei, Xiao Chengbo, Ling Chengjian. Sichuan Tibetan Traditional Architecture Structure Survey [J] "Sichuan Building Science research" 2013.04.P93-98. 